\title{
Control Methods for Low Voltage Ride-Through Compliance in Grid-Connected NPC Converter Based Wind Power Systems Using Predictive Control
}

\author{
S. Alepuz ${ }^{(1)}$, S. Busquets-Monge ${ }^{(1)}$, J. Bordonau $^{(1)}$, P. Cortés ${ }^{(2)}$, S. Kouro ${ }^{(3)}$ \\ ${ }^{(1)}$ Dept. Electronic Engineering \\ Technical University of Catalonia \\ Barcelona, Spain \\ alepuz@eupmt.es
Universidad Téc. Federico Santa María
Valparaíso, Chile
patricio.cortes@usm.cl \\ ${ }^{(2)}$ Depto. Electrónica
Ryerson University
Toronto, Canada
samir.kouro@ieee.org \\ ${ }^{(3)}$ Dept. Electrical and Computer Eng.
}

\begin{abstract}
In presence of grid voltage dips, Low Voltage Ride-Through (LVRT) requirements demand the wind power plant to remain connected to the grid, helping the network to keep voltage and frequency stable. Neutral-Point-Clamped (NPC) converters are appropriate for wind power systems, because the current trend of increasing voltage levels. Predictive current control presents as fast dynamic response and accurate reference tracking as other well established control methods, while providing more flexibility. In this work, three different control strategies are applied to the grid-side NPC converter, in order to fulfil LVRT requirements, which are implemented with the predictive current control technique. Dc-link neutral point voltage is kept balanced by the predictive control algorithm, using the redundant switching states of the NPC converter. Simulation results confirm the validity of the proposed control approach.
\end{abstract}

Index Terms--Predictive control, wind-power system, wind power generation, distributed power generation, grid interface, multilevel inverters, NPC inverter.

\section{INTRODUCTION}

The total installed wind power world capacity reached 120 $\mathrm{GW}$ at the end of 2008 [1]. In recent years, power systems operators have included wind power plants in the transient operation control of the overall power system, as shown in the grid connection requirements (GCR) [2], [3]. Among the GCR, LVRT requirements demand wind power plants to remain connected when a grid dip occurs, contributing to keep network voltage and frequency stable by delivering active and reactive power to the grid with a specific profile depending on the grid voltage dip depth.

LVRT requirements are shown in Fig. 1 and Fig. 2. The power generation plant is not allowed to be disconnected from the grid if the line voltage is above the limit curve in Fig. 1. During the dip, the wind power plant has to inject some quantity of reactive power into the grid according to Fig. 2; in order to help the power system to counteract the grid voltage drop. As shown in Fig. 2, the quantity of reactive power to be injected depends on the percentage of grid voltage reduction during the dip, and the system rated current. For example, the full rated current has to be

This work has been supported by grants TEC2005-08042 and TEC200801794, Ministerio de Ciencia y Tecnología (Spain), and by grant 2009 BE1 444, Departament d'Universitats, Recerca i Societat de la Informació de la Generalitat de Catalunya (Spain).

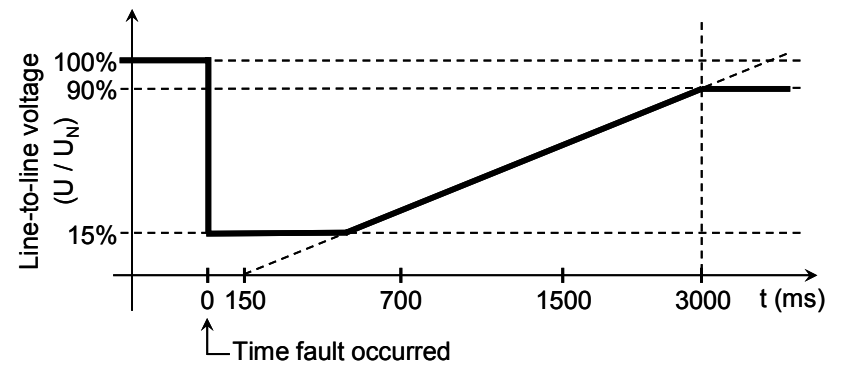

Fig. 1. Voltage limit curve to allow wind turbine disconnection.

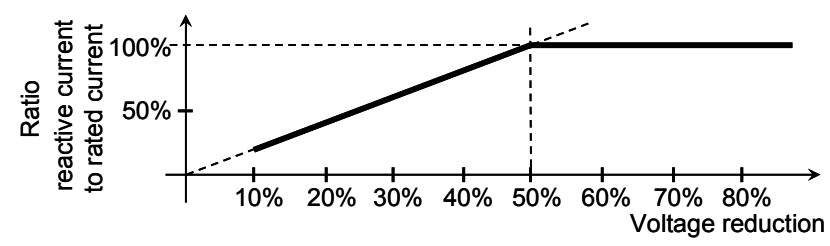

Fig. 2. Reactive current to be fed under a voltage dip.

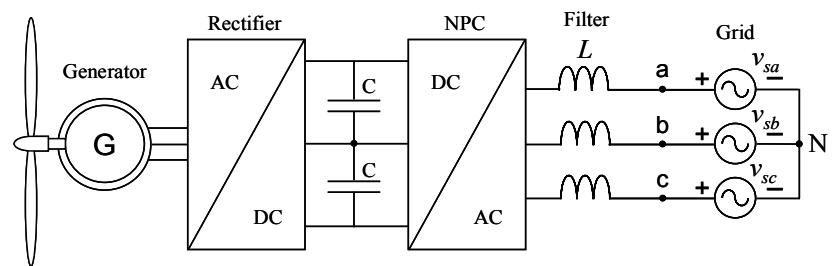

Fig. 3. Wind generator connected to the grid through a full power back-to-back NPC converter.

delivered to the grid as reactive current for dips with a voltage reduction larger than $50 \%$, and no active power is injected into the grid. Therefore, for the duration of the dip, active and reactive power references, this is, current references, have to be set accordingly with the requirement shown in Fig. 2.

Other challenges the grid converter has to face are the current trends to increase the power rating of the wind turbines and to meet more demanding power quality grid codes. This new trends make the NPC multilevel converter a suitable grid interface for wind power systems [4], [5].

This work deals with the grid-side converter of the full power back-to-back NPC converter, which connects a wind turbine to the grid [5], as shown in Fig. 3. Generator-side converter and its control have not been considered in this 


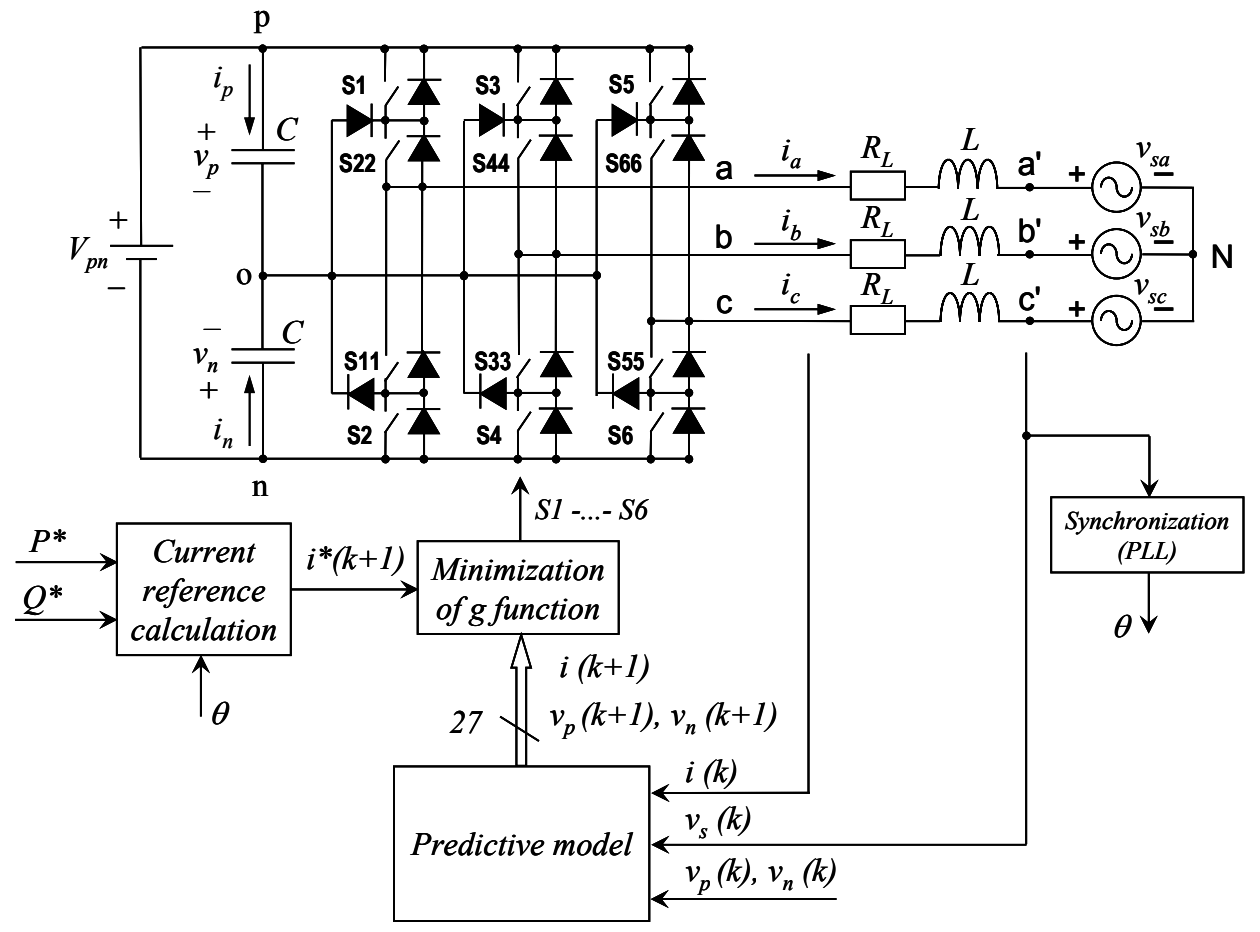

Fig. 4. NPC converter connected to the grid through a $L$ filter and simplified control block diagram.

work, as justified in [6]. For the grid-side NPC converter, three control strategies to meet LVRT based on symmetrical components implemented with Linear Quadratic Regulator (LQR) have been compared in [6], with fast and accurate performance, but it seems that transient operation can be improved. On the other hand, in comparison with well established control techniques, predictive control [7] achieves better dynamic response and reference tracking, working at similar switching frequencies [8].

In this contribution, the same three control strategies in [6] are applied to the grid-side NPC converter, but implemented with predictive current control [7]-[9]. With this approach, some improvement in the transient operation is found. Dclink neutral point balance is achieved by means of the predictive control algorithm, using the redundant switching states of the NPC converter.

\section{Model of THE SYSTEM AND CONTROL Method}

The system and the control approach considered in this work is shown in Fig. 4. The dc-link voltage has been assumed constant [6], [10], [11] and, subsequently, generator-side and grid-side converter control can be considered decoupled, both in steady-state and transient operation. The current reference calculation is performed using three different ways to meet LVRT requirements [6], and the predictive current controller guarantees fast and accurate current reference tracking [8].

\section{A. Current reference calculation}

The first method of current reference calculation generates symmetrical and balanced grid currents in all conditions, as the vector current controller with feedforward of negative sequence grid voltage (VCCF) in [12]. Symmetrical and balanced current references are set to meet the requirements in Fig. 2, and can be easily calculated from the power references.

The second and third type of current reference calculation are as the dual vector current controllers (DVCC) in [12], and are implemented with the block scheme shown in Fig. 5.

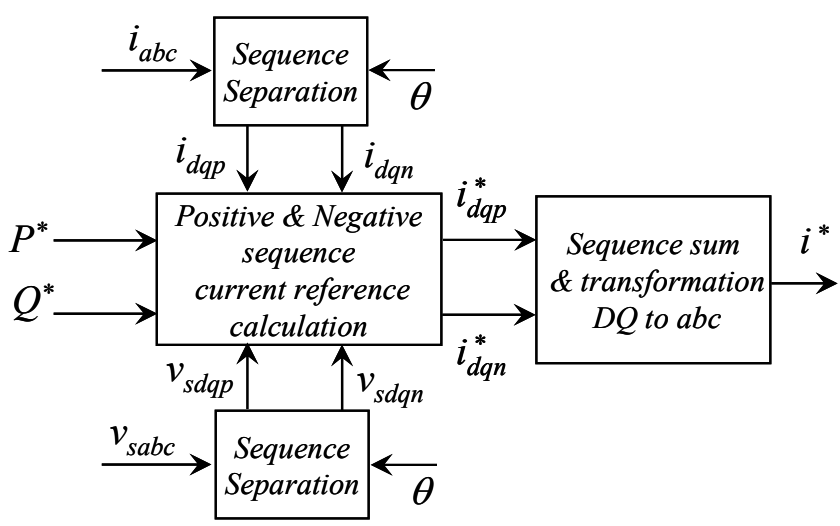

Fig. 5. Block diagram for the current reference calculation as DVCC. 
The apparent power at grid terminals calculated with positive- and negative-sequence components is

$$
\left[\begin{array}{c}
P \\
P_{2 c} \\
P_{2 s} \\
Q \\
Q_{2 c} \\
Q_{2 s}
\end{array}\right]=\left[\begin{array}{cccc}
v_{s d p} & v_{s q p} & v_{s d n} & v_{s q n} \\
v_{s d n} & v_{s q n} & v_{s d p} & v_{s q p} \\
v_{s q n} & -v_{s d n} & -v_{s q p} & v_{s d p} \\
v_{s q p} & -v_{s d p} & v_{s q n} & -v_{s d n} \\
v_{s q n} & -v_{s d n} & v_{s q p} & -v_{s d p} \\
-v_{s d n} & -v_{s q n} & v_{s d p} & v_{s q p}
\end{array}\right] \cdot\left[\begin{array}{c}
i_{d p} \\
i_{q p} \\
i_{d n} \\
i_{q n}
\end{array}\right],
$$

where $P$ and $Q$ are the constant or mean active and reactive power, respectively, while $P_{2 c}, P_{2 s}, Q_{2 c}, Q_{2 s}$ are the second harmonic cosine and sine component of the active and reactive power, terms that appear when the three-phase system is not symmetrical and balanced. Depending on how oscillating active powers are treated in (1), there are two different methods to calculate current references.

The active power dissipated in the filter can play a significant role in the current reference calculation [6]. This power presents different terms [12]: constant or average term (2), second harmonic cosine (3) and sine (4) terms.

$$
\begin{aligned}
& \Delta P=R_{L} \cdot\left(i_{d p}^{2}+i_{q p}^{2}+i_{d n}^{2}+i_{q n}^{2}\right) \\
& \Delta P_{2 c}=2 R_{L} \cdot\left(i_{d p} \cdot i_{d n}+i_{q p} \cdot i_{q n}\right)+2 \omega L \cdot\left(i_{d p} \cdot i_{q n}-i_{q p} \cdot i_{d n}\right) \\
& \Delta P_{2 s}=2 R_{L} \cdot\left(i_{d p} \cdot i_{d n}-i_{q p} \cdot i_{q n}\right)+2 \omega L \cdot\left(-i_{d p} \cdot i_{q n}-i_{q p} \cdot i_{d n}\right)
\end{aligned}
$$

The second method (DVCC1) considered here calculates current references (5) by setting active and reactive power references $\left(P^{*}, Q^{*}\right)$, and nullifying the oscillating active power delivered to the grid $\left(P_{2 c} *=P_{2 s} *=0\right)$. In this case, the oscillating active power flows between the filter and the dclink. In order to work with an invertible matrix $(4 \times 4)$, oscillating reactive power $\left(Q_{2 c}, Q_{2 s}\right)$ can not be included in the current reference calculation (5). Therefore, oscillating reactive power is not controlled and will flow through the system.

$$
\left[\begin{array}{c}
i_{d p}^{*} \\
i_{q p}^{*} \\
i_{d n}^{*} \\
i_{q n}^{*}
\end{array}\right]=\left[\begin{array}{cccc}
v_{s d p} & v_{s q p} & v_{s d n} & v_{s q n} \\
v_{s d n} & v_{s q n} & v_{s d p} & v_{s q p} \\
v_{s q n} & -v_{s d n} & -v_{s q p} & v_{s d p} \\
v_{s q p} & -v_{s d p} & v_{s q n} & -v_{s d n}
\end{array}\right]^{-1} \cdot\left[\begin{array}{c}
P^{*} \\
0 \\
0 \\
Q^{*}
\end{array}\right]
$$

The third method (DVCC2) calculates the current references (6) by setting active and reactive power references $\left(P^{*}, Q^{*}\right)$, and by forcing the oscillating active power demanded by the filter to be delivered from the grid $\left(P_{2 c}{ }^{*}=\right.$ $\left.-\Delta P_{2 c} ; P_{2 s}{ }^{*}=-\Delta P_{2 s}\right)$. Then, no oscillating active power flows between the dc link and the filter.

$$
\left[\begin{array}{c}
i_{d p}^{*} \\
i_{q p}^{*} \\
i_{d n}^{*} \\
i_{q n}^{*}
\end{array}\right]=\left[\begin{array}{cccc}
v_{s d p} & v_{s q p} & v_{s d n} & v_{s q n} \\
v_{s d n} & v_{s q n} & v_{s d p} & v_{s q p} \\
v_{s q n} & -v_{s d n} & -v_{s q p} & v_{s d p} \\
v_{s q p} & -v_{s d p} & v_{s q n} & -v_{s d n}
\end{array}\right]^{-1} \cdot\left[\begin{array}{c}
P^{*} \\
-\Delta P_{2 c} \\
-\Delta P_{2 s} \\
Q^{*}
\end{array}\right]
$$

\section{B. Predictive current control}

The predictive current control algorithm is based on the discrete system model

$$
i(k+1)=\frac{T_{s}}{R \cdot T_{s}+L} \cdot\left[\frac{L}{T_{s}} \cdot i(k)+v(k)-v_{s}(k)\right],
$$

used to obtain predictions for the future value of the line current $i(k+1)$, considering all possible voltage vectors $v(k)$ generated by the inverter, the measured line current vector $i(k)$ and the grid voltage vector $v_{s}(k)$, where $L$ is the filter inductance, $R_{L}$ the filter resistance, and $T_{s}$ the sampling period. The voltages of the dc-link capacitors are predicted by

$$
v_{p, n}(k+1)=v_{p, n}(k)+\frac{1}{C} i_{p, n}(k) \cdot T_{s} .
$$

Currents through the capacitors are calculated using the line currents and the present switching state $\left(i_{p}(k), i_{n}(k)\right.$ are the currents through each dc-link capacitor; $v_{p}(k), v_{n}(k)$ are the dc-link capacitor voltages; $C$ is the capacitance value).

The future value of the line current $i(k+1)$ and the capacitor voltages $v_{p}(k+1)$ and $v_{n}(k+1)$ are predicted for the 27 switching states generated by the NPC inverter shown in Fig. 6, using the predictive model given by (7) and (8).

After obtaining the predictions, a quality function $g(9)$ is evaluated for each switching state. The switching state that minimizes $g$ is selected and applied during the next sampling period [13]. The first term in the proposed quality function $g$ (9) is dedicated to achieve reference tracking, and the second term is dedicated to balance the dc-link voltages.

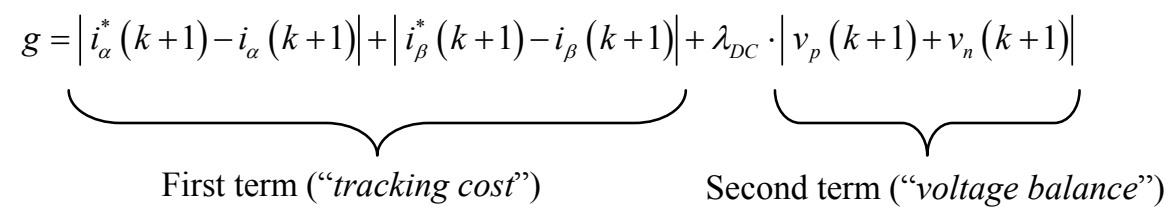




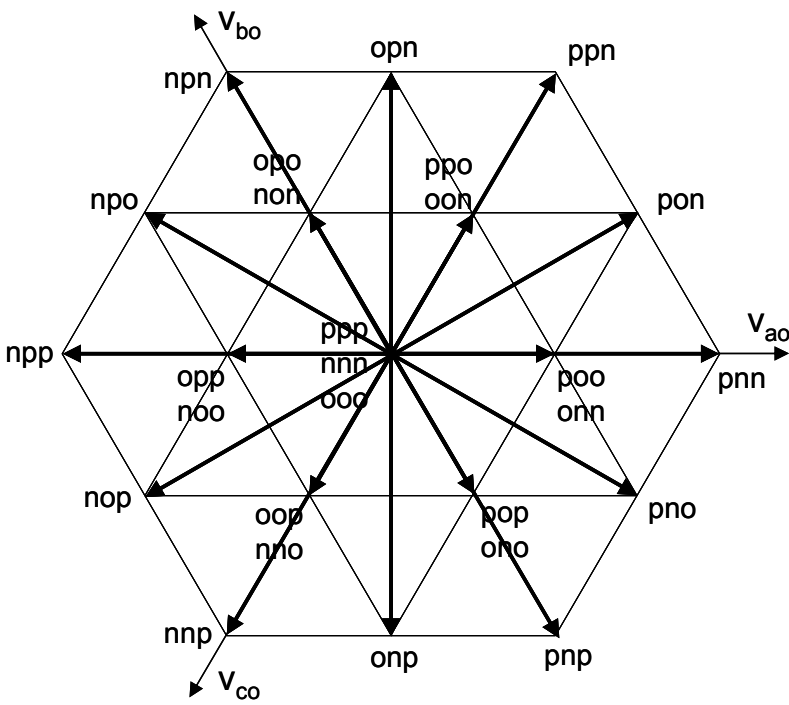

Fig. 6. Possible voltage vectors and switching states generated by a three-level inverter.

The weighting factor $\lambda_{D C}$ handle the relation between both terms within the quality function $g$. In general, the weighting factor is used to decouple different variables in the quality function that have different units and orders of magnitudes, so they are equally represented (or even represented at will depending on the requirements). In this work, a weighting factor $\lambda_{D C}=1$ has been selected simply to include in the quality function the term dedicated to balance the dc-link voltages. However, a simple and effective method to calculate the weighting factors within the quality function in predictive control is described in [14].

\section{Simulation RESUltS}

Simulation results for the proposed control strategies are presented. The specifications for the system in Fig. 4 are: $L=$ $10 \mathrm{mH} ; R_{L}=0.1 \Omega ; C=750 \mu \mathrm{F} ; V_{p n}=1000 \mathrm{~V} ; V_{G R I D}=$ $400 \mathrm{~V}_{\mathrm{RMS}} ; f=50 \mathrm{~Hz} ; T_{s}=100 \mu \mathrm{s}$.

The system with the three different controllers has been tested under a grid voltage dip type $\mathrm{C}$ with $50 \%$ voltage drop and $30^{\circ}$ phase shift and a $90 \%$ grid voltage dip type B [15]. $P$ and $Q$ references are set to $10 \mathrm{~kW}$ and $0 \mathrm{VAR}$ in steady-state and switched to $0 \mathrm{~kW}$ and $10 \mathrm{kVAR}$ during the dip, in order to meet LVRT requirements [2], [3].

Results for the $50 \%$ grid voltage dip type C [15] depicted in Fig. 7 are shown in Figs. 8-11 for the three controllers. For the VCCF method, the current references are balanced, as depicted in Fig. 8a. Balanced grid currents are obtained, as illustrated in Fig. 9a. Good current reference tracking is observed by comparing Fig. 8a and Fig. 9a. The unbalanced grid voltages together with the balanced line currents causes the instant active and reactive power to oscillate. However, the average values show that only reactive power is delivered to the grid during the dip, as shown in Fig. 10a. The dc-link voltages are balanced in all conditions, as shown in Fig. 11a.

In contrast, for the DVCC1 and DVCC2 methods, unbalanced current references and grid currents are obtained, as can be appreciated in Figs. 8b, 8c, 9b and 9c. Accurate reference tracking is achieved. In addition, peak currents are larger than the VCCF method because the current reference generator does not directly control currents, but power. This could lead to filter saturation or line overcurrent.

For the VCCF method, note that instant active and reactive power oscillate, as shown in Fig. 10a. No oscillating active power is delivered to the grid with the DVCC1 method, but larger oscillating reactive power is found, as can be corroborated in Fig. 10b. In comparison to the VCCF method, the results with the DVCC2 method shown in Fig. 10c presents smaller oscillating active power but larger oscillating reactive power. Oscillating powers delivered to the grid can affect the control of the network voltage and frequency under distorted condition.

On the other hand, results for the $90 \%$ grid voltage dip type B [15] shown in Fig. 12 are illustrated in Figs. 13 to 16 for the three controllers. Note that these results corroborate completely the assertions made above for the grid voltage type $\mathrm{C}$.

For the DVCC methods, a sequence separation method is needed to obtain positive- and negative-sequences of grid voltages and currents, in order to calculate current references. In this work, delayed signal cancellation [16] method has been used for this purpose. This technique presents an intrinsic delay of $5 \mathrm{~ms}$ (for a grid period $T=20 \mathrm{~ms}$ ), which does not affect under steady state operation, but makes an inaccurate sequence separation during the first $5 \mathrm{~ms}$ after the appearance of any grid transient. During this interval of time, inaccurate values are fed back to the control system. The result of these inaccuracies can be observed in the currents and power performance results during the $5 \mathrm{~ms}$ after the fault appearance and clearance. Despite of these inaccuracies, the results obtained are satisfactory in all cases.

For the DVCC2 method, the grid currents ripple is significantly higher than for the VCCF and DVCC1 methods. This ripple has its origin at the current reference calculation, as can be observed in Fig. $8 \mathrm{c}$ and 13c. It is likely produced by the terms $\left(P_{2 c}{ }^{*}=-\Delta P_{2 c} ; P_{2 s}{ }^{*}=-\Delta P_{2 s}\right)$ used in (6). This ripple does not depend on the type of controller used, because it has been already observed in [6], where a multivariable optimal control has been applied. This effect is also reflected in the dc-link unbalance voltage shown in Figs. $11 \mathrm{c}$ and $16 \mathrm{c}$, which present different performance than the VCCF and DVCC1 methods.

The predictive current controller performance is fast, and accurate current reference tracking is found in all cases, as deduced by comparing current references and grid currents. Also, dc-link neutral point voltage is balanced in all cases, which can be appreciated in Figs. 11 and 16. 


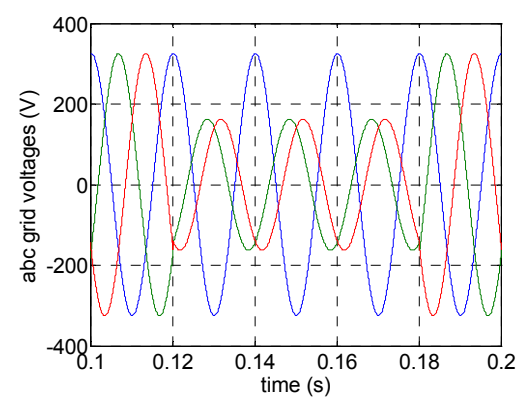

Fig. 7. Grid Voltages. $50 \%$ dip type C.

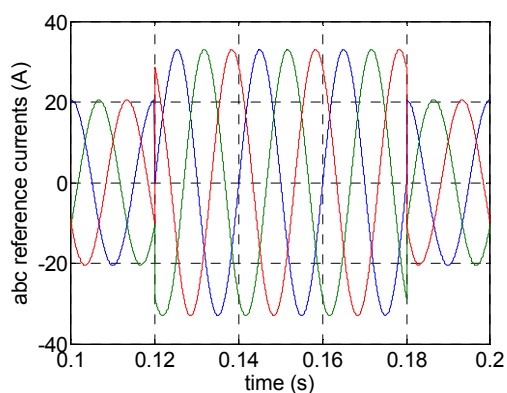

Fig. 8a. Current reference. VCCF.

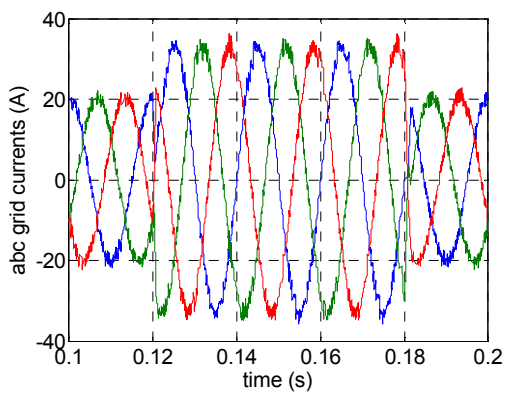

Fig. 9a. Grid currents. VCCF.

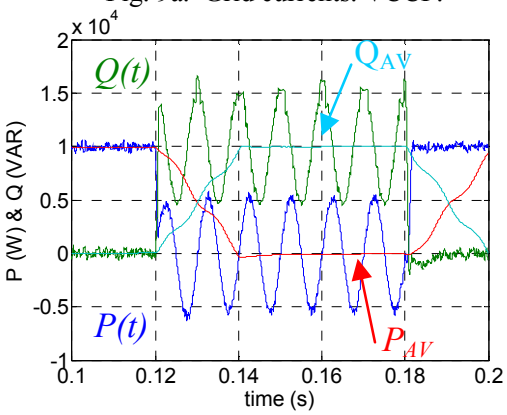

Fig. 10a. $P(t), Q(t), P_{A V}, Q_{A V}$. VCCF.



Fig. 11a. Dc-link voltage unbalance. VCCF.
The simulation results demonstrate that all the three controllers fulfil the LVRT requirement. The three controllers regulate average active and reactive power as the LVRT requirement demands, and only average reactive power is delivered to the grid during the dip.

In comparison with the implementation in [6], the proposed control approach presented here shows similar performance for VCCF and DVCC1, and slight better transient performance for DVCC2.

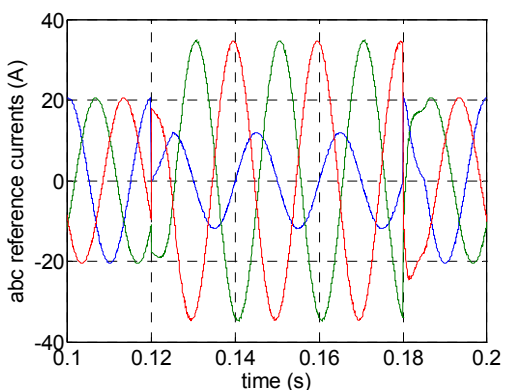

Fig. 8b. Current reference. DVCC1.

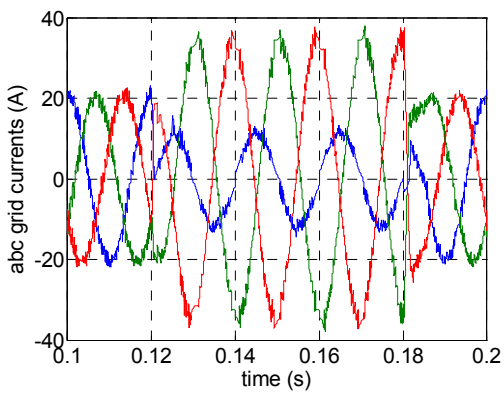

Fig. 9b. Grid currents. DVCC1.

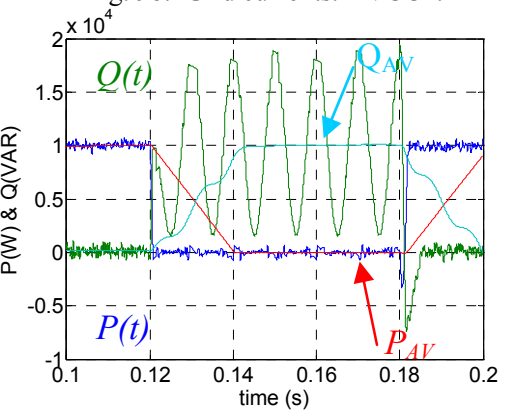

Fig. 10b. $P(t), Q(t), P_{A V}, Q_{A V}$. DVCC1.

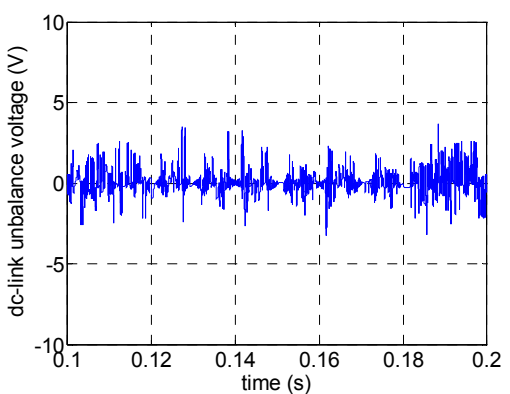

Fig. 11b. Dc-link voltage unbalance. DVCC1.

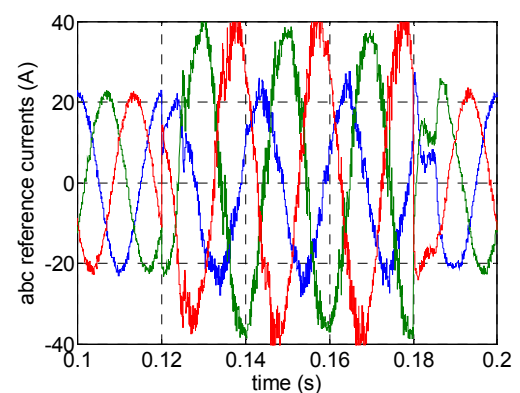

Fig. 8c. Current reference. DVCC2.

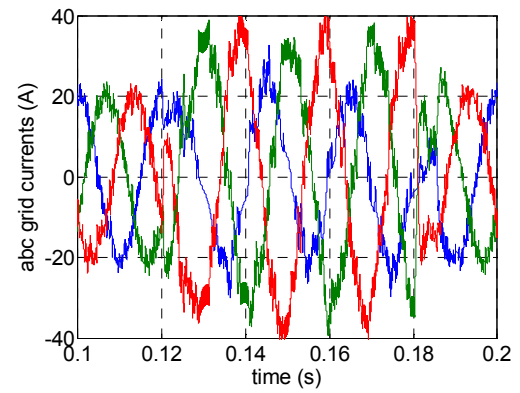

Fig.9c. Grid currents. DVCC2.

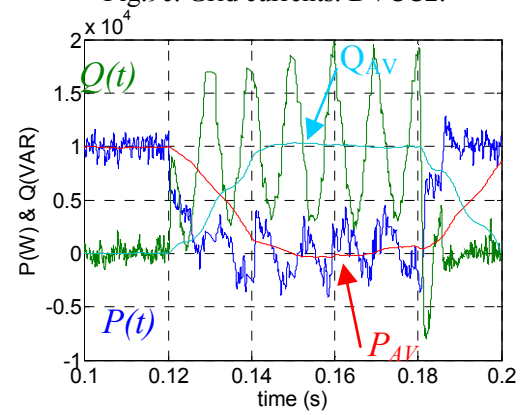

Fig. 10c. $P(t), Q(t), P_{A V}, Q_{A V}$. DVCC2.

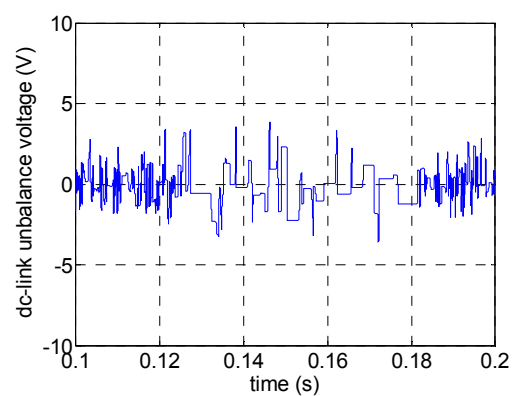

Fig. 11c. Dc-link voltage unbalance. DVCC2. 


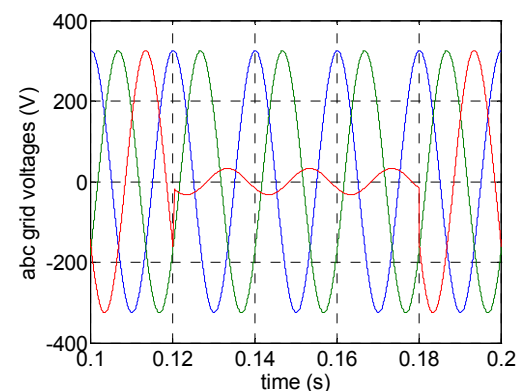

Fig. 12. Grid Voltages. $90 \%$ dip type B.

\section{CONCLUSIONS}

A predictive current controller for grid-connected NPC to meet LVRT requirements in wind power systems has been presented. Three current reference calculation methods for the predictive control have been considered.

In normal grid operation, the usual approach is to deliver line currents in phase with grid voltages, and the power is injected to the grid with unity power factor. However, the power factor can be regulated responding to the command from the electric power system operator.

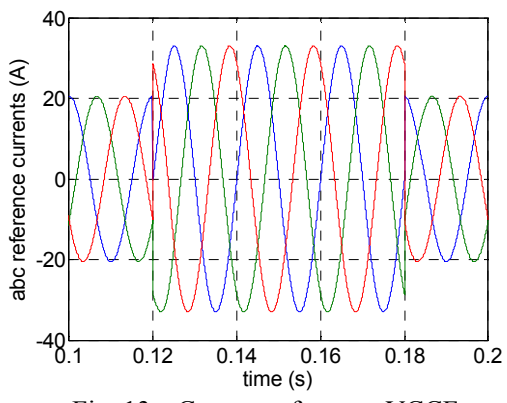

Fig. 13a. Current reference. VCCF.

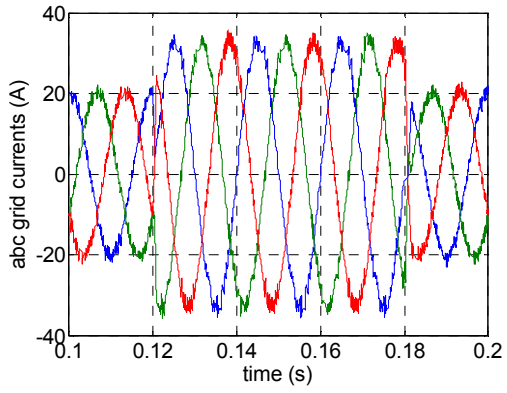

Fig. 14a. Grid currents. VCCF.

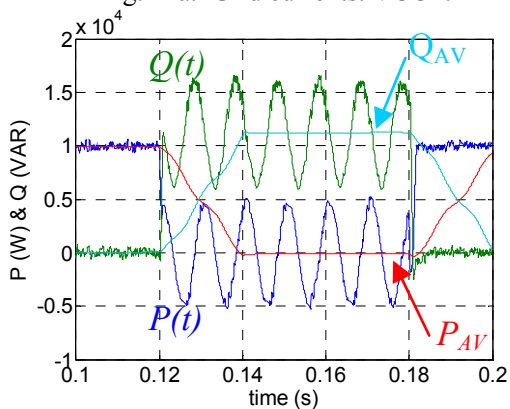

Fig. 15a. $P(t), Q(t), P_{A V}, Q_{A V}$. VCCF.

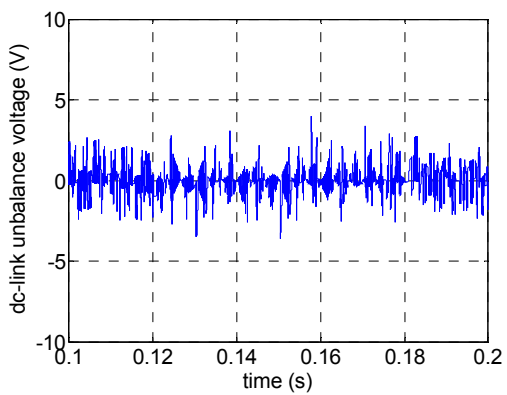

Fig. 16a. Dc-link voltage unbalance. VCCF.

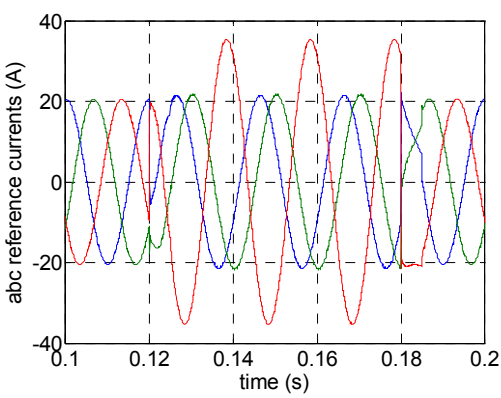

Fig. 13b. Current reference. DVCC1.

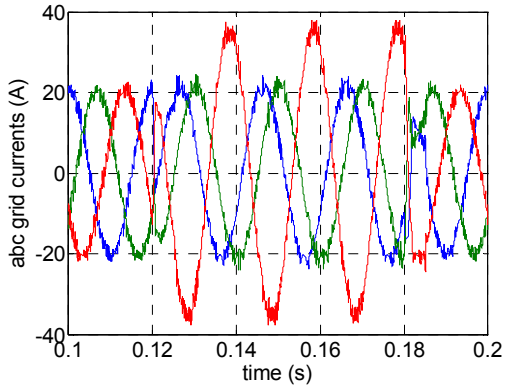

Fig. 14b. Grid currents. DVCC1.

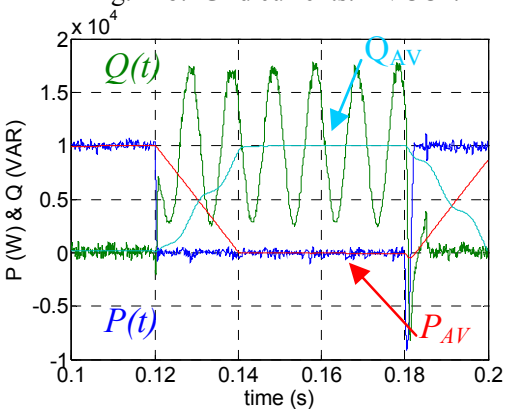

Fig. 15b. $P(t), Q(t), P_{A V}, Q_{A V}$. DVCC1

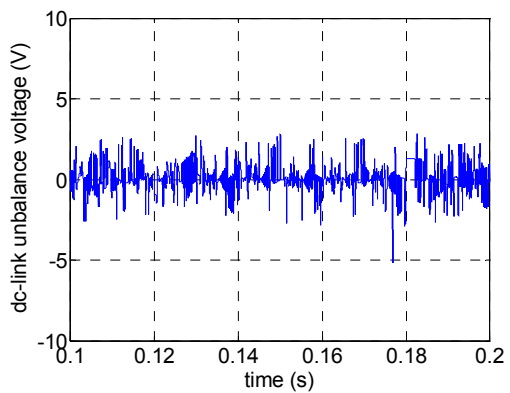

Fig. 16b. Dc-link voltage unbalance. DVCC1.

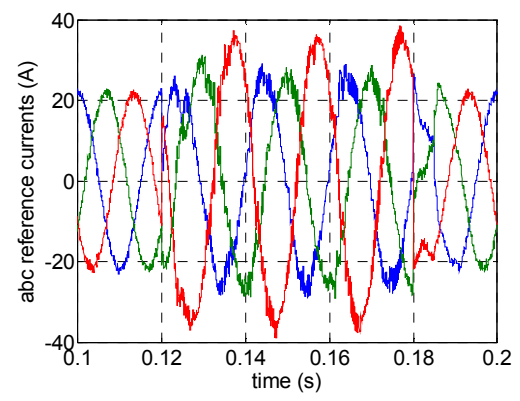

Fig. 13c. Current reference. DVCC2.

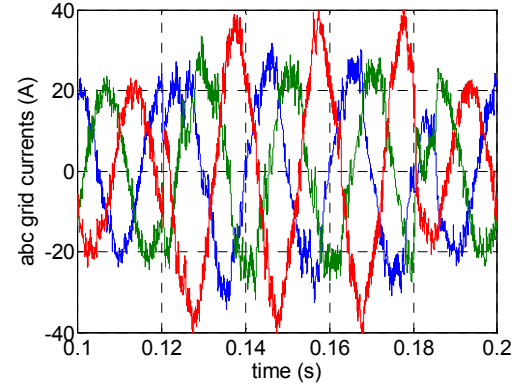

Fig. 14c. Grid currents. DVCC2.

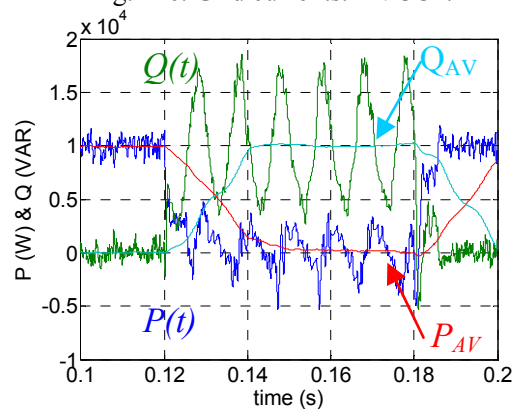

Fig. 15c. $P(t), Q(t), P_{A V}, Q_{A V}$. DVCC2.

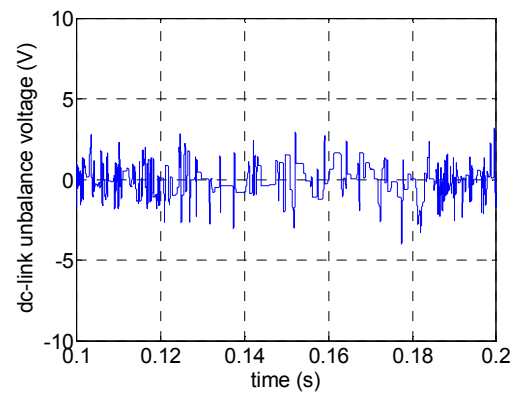

Fig. 16c. Dc-link voltage unbalance. DVCC2. 
When a grid dip appears, the current reference is changed to meet LVRT requirements. Current reference tracking performance given by the predictive controller is fast, accurate and presents no overshoot. All the three considered controllers comply with the LVRT requirements.

Oscillating instant active and reactive power are present during the dip, as a result of the unbalanced grid voltages and balanced grid currents. However, this is not an obstacle to verify LVRT requirements. Other control strategies in the literature avoid these oscillations, at the expense of having unbalanced grid currents.

In parallel, the predictive controller uses the redundant states of the three-level inverter to maintain the dc-link voltage balance for the three controllers in all conditions.

\section{REFERENCES}

[1] Wind Energy Barometer European Commission 2009. Systèmes Solaires - Le journal de l'éolien, No. 4, pp. 45-79, Feb. 2009.

[2] Grid Code. High and extra high voltage. E.ON Netz. August 2003. www.eon-netz.com. Germany.

[3] Red Eléctrica. Procedimiento de operación P.O. 12.3: Requisitos de respuesta frente a huecos de tensión de las instalaciones de producción en régimen especial. Oct. 2006. www.ree.es. Spain.

[4] S. Alepuz, S. Busquets, J. Bordonau, J. Gago, D. González, J. Balcells, "Interfacing Renewable Energy Sources to the Utility Grid using a Three-Level Inverter". IEEE Transactions on Industrial Electronics. Vol. 53, No. 5, pp. 1504-1511, Oct. 2006.

[5] J.Carrasco, L. Garcia Franquelo, J. T. Bialasiewicz, E. Galván, R. C. Portillo Guisado, M. Á. Martín Prats, J. I. León, N. Moreno-Alfonso, "Power-Electronic Systems for the Grid Integration of Renewable Energy Sources: A Survey". IEEE Transactions on Industrial Electronics, Vol. 53, No. 4, pp. 1002-1016, Aug. 2006.

[6] S. Alepuz, S. Busquets-Monge, J. Bordonau, J. A. Martinez-Velasco, C. Silva, J. Pontt, J. Rodriguez, "Control Strategies Based on Symmetrical Components for Grid-Connected Converters Under Voltage Dips". IEEE Transactions on Industrial Electronics, Vol. 56, No. 6, pp. 2162 2173. Jun. 2009.

[7] E. Camacho and C. Bordons, Model Predictive Control. New York: Springer-Verlag, 1999.

[8] R. Vargas, P. Cortes, U. Ammann, J. Rodriguez, J. Pontt, "Predictive Control of a Three-Phase Neutral-Point-Clamped Inverter", IEEE Transactions on Industrial Electronics, vol. 54, pp. 2697-2705, 2007.

[9] S. Alepuz, S. Busquets-Monge, J. Bordonau, P. Cortés, J. Rodríguez, R. Vargas. "Predictive Current Control of Grid-Connected Neutral-PointClamped Converters to meet Low Voltage Ride-Through Requirements". IEEE Power Electronics Specialist Conference (PESC'08). Vol. 1, pp. 2423-2428. 15-19 June, 2008. Rhodes, Greece.

[10] J. F. Conroy, R. Watson, "Low-Voltage Ride-Through of a Full Converter Wind Turbine with Permanent Magnet Generator". IET Renewable Power Generation, Vol. 1, No. 3, pp. 182 - 189, Sept. 2007.

[11] M. Eichler, P. Maibach, A. Faulstich, "Full Size Voltage Converters for 5MW Offshore Wind Power Generators". European Wind Energy Conference \& Exhibition. EWEC'08. Poster 161. 31 Mar-3 Apr, 2008.

[12] F.Magueed, A.Sannino, J.Svensson, "Transient Performance of Voltage Source Converter under Unbalanced Voltage Dips".IEEE Power Electronics Specialist Conference (PESC'04). Vol. 2, pp. 1163-1168, 20-25, Jun. 2004.

[13] S. Kouro, P. Cortes, R. Vargas, U. Ammann, J. Rodriguez. "Model Predictive Control-A Simple and Powerful Method to Control Power Converters". IEEE Transactions on Industrial Electronics, vol. 56, no. 6, pp. 1826-1838, Jun. 2009.

[14] P. Cortes, S. Kouro, B. La Rocca, R. Vargas, J. Rodriguez, J. I. Leon, S. Vazquez, L. G. Franquelo. "Guidelines for Weighting Factors Design in Model Predictive Control of Power Converters and Drives". IEEE International Conference on Industrial Technology, IEEE-ICIT09, Gippsland, Australia, 10-13 Feb. 2009.
[15] M.Bollen, Understanding power quality problems: voltage sags and interruptions, IEEE Press, 1999.

[16] G.Saccomando, J.Svensson, "Transient Operation of Grid-Connected Voltage Source Converter Under Unbalanced Conditions". IEEE Industry Applications Conference (IAS'01). Vol. 4, pp. 2419-2424, 30 Sept.-4 Oct. 2001. 